\title{
GRATUIDADE DO ENSINO SUPERIOR EM ESTABELECIMENTOS OFICIAIS: PRECISÃO E IMPLICAÇÕES*
}

\author{
Lalo Watanabe Minto ${ }^{1}$
}

\begin{abstract}
RESUMO: Neste estudo tratamos do princípio constitucional da gratuidade do ensino público em estabelecimentos oficiais (art. 206) como extensivo e obrigatório também para o nível superior. Assumimos que essa extensividade também implica obediência, no caso das universidades oficiais/públicas, a outro princípio particular dessas instituiçóes: o da indissociabilidade entre ensino, pesquisa e extensão (art. 208). A partir de uma leitura global do capítulo sobre educação na Constituição Federal de 1988 (CF 1988) e de seus desdobramentos na Lei de Diretrizes e Bases da Educação Nacional (LDB 1996), em especial no capítulo "Da Educação Superior", afirmamos que incorre em infração a prática de cobrar mensalidades, taxas e outras formas de cobrança nas universidades mantidas pelo Poder Público. Nas consideraçóes finais, apresentamos uma discussão sobre os atuais contornos da gratuidade do ensino superior público, bem como sobre os renovados argumentos em prol da sua extinção, dentro e fora das instituiçôes.
\end{abstract}

Palavras-chave: Educação superior. Universidade oficial. Gratuidade.

\section{THE PUBLIC HIGHER EDUCATION IN OFFICIAL ESTABLISHMENTS: ACCURACY AND IMPLICATIONS}

ABSTRACT: This paper deals with the constitutional principle of free public education in official establishments (art. 206) as extensive and compulsory also for the higher education. In the case of public universities, it is assumed that such extension implies compliance with another specific principle: the indissolubility between teaching, research, and extension (art. 208). From an overall reading of the chapter on education in the Federal Constitution of 1988 and its developments in the Law of Guidelines and Bases of National Education (LDB 1996), especially in the chapter "On Higher Education", one may affirm that the practice of collecting monthly fees, taxes, and other forms of billing in universities maintained by the public power violates these superior

\footnotetext{
*Estudo decorrente do projeto de pesquisa Gratuidade e caráter público do ensino superior no Brasil: configuração atual e tendências, financiado pela FAEPEX/Unicamp.

${ }^{1}$ Universidade Estadual de Campinas, Programa de Pós-Graduação em Educação - Campinas (SP), Brasil. E-mail: lalo@unicamp.br

DOI: 10.1590/ES0101-73302018181580
} 
rules. In final considerations, a discussion about the current frame of free public higher education is presented, along with renewed arguments supporting its extinction, inside and outside institutions.

Keywords: Higher education. Public university. Gratuity.

\section{L'ÉDUCATION SUPÉRIEUR GRATUITE DANS LES ÉTABLISSEMENTS OFFICIELS: PRÉCISION ET CONSÉQUENCES}

RESUMÉ: Cette étude porte sur le principe constitutionnel de l'enseignement public gratuit dans les établissements officiels (art. 206) comme obligatoire également au niveau supérieur. Nous partons du principe que cette extensification implique également l'obéissance, dans le cas des universités officielles/publiques, à un autre principe particulier de ces institutions: l'inséparabilité de l'enseignement, la recherche et l'extension (art. 208). A partir d'une lecture globale de la Constitution Fédérale de 1988 et ses déploiements dans la Loi de Lignes Directrices et les Bases de L'Éducation Nationale (LDB 1996), en particulier le chapitre "De L'Enseignement Supérieur », nous affirmons que la pratique de faire payer les frais de scolarité et autres frais dans les universités tenus par le gouvernement est une infraction à la loi. Dans les considérations finales, nous présentons une discussion sur la forme en vigueur de l'enseignement supérieur public gratuit, ainsi que des arguments renouvelés qui plaident en faveur de son extinction, dans et hors des institutions.

Mots-clés: Enseignement supérieur. Université public. Gratuité.

A

gratuidade do ensino superior (ES) estatal se tornou uma garantia constitucional em 1988, embora já existisse, de fato, desde os anos 1950 (CUNHA, 1999, p. 42). No percurso que antecedeu essa conquista, a expansão do ES veio sendo, cada vez mais, acompanhada da demanda pela gratuidade, que, já na Primeira República “aparecia como elemento importante de ingresso, até mesmo condição necessária para isso" (CUNHA, 1991, p. 32).

Antes de 1988, vigorou apenas o mecanismo da "gratuidade condicionada”, incorporada pelas Constituições de 1934, 1946, 1967 e revisão de 1969. Para Cunha (1991, p. 37), esse foi um período em que as demandas pela gratuidade foram equacionadas no âmbito das práticas populistas dos governos brasileiros, com vistas a atender aos anseios da classe média. Isso ocorreu até atingir o ponto em que, mesmo náo sendo garantida constitucionalmente, a gratuidade passou a ser entendida como direito, em especial pelo movimento estudantil.

Posiçóes contrárias à gratuidade do ES tiveram forte ascensão durante a Ditadura (1964-85). O tema foi defendido pelas forças de sustentação do re- 
gime, estando presente nos principais documentos que forneceram diretrizes e orientaram as reformas, pelo menos, desde o Plano de Ação Econômica do Governo (1964-1966) ${ }^{1}$. Em regra, as propostas orbitavam a noção de que grande parte do público que acessava o ES tinha "condição de pagar", o que não justificaria a gratuidade. Cunha (1991, p. 37) explica que os grupos políticos que se aliaram aos militares eram os mesmos que defendiam a "modernização" das instituiçôes educacionais segundo o padrão estadunidense, no qual prevalecia a concepção de que a educação superior era um gasto que "resultava em benefícios econômicos para os indivíduos". No período, também vicejaram proposiçôes como a da obtenção de "fontes alternativas" de recursos para as Instituiçóes de Ensino Superior (IES), por meio da venda de produtos e serviços, doaçóes de pessoas físicas e jurídicas, entre outras (MINTO, 2006, p. 118-125).

Apesar dessas características dominantes, com destaque para o crescente interesse comercial que animava certos setores de classe para com a educação, a recuperação econômica do período de 1968 a 1973 propiciou outras saídas ao ES e reduziu, em certa medida, as pressóes antigratuidade. A opção conservadora de expandir o ES privado foi uma das maneiras de responder ao problema da demanda que acirrava a luta em torno da gratuidade nas IES estatais. Segundo Cunha (1991, p. 42), a criação de um programa de crédito educativo (embriáo do que viria a ser o FIES, anos mais tarde) também ajudou a dirimir tais pressóes.

Mas é um fato que, desde a instituição da gratuidade ampla e irrestrita, em 1988, as forças antigratuidade se ampliaram e diversificaram. Projetos para instituir cobranças têm sido apresentados nas Casas Legislativas ${ }^{2}$ e o assunto tornou-se recorrente na chamada opiniáo pública. Isso vem se dando num contexto de crise capitalista (estrutural), de modo que, no neoliberalismo, encontra-se uma das expressóes político-ideológicas das novas demandas por reestruturação das relaçóes entre Estado, capital e políticas sociais, com consequências diretas no padrão de financiamento estatal do ES.

O objetivo desse estudo é especificar quais são as regras vigentes para a gratuidade do ES nos estabelecimentos oficiais, discutindo sua abrangência e suas consequências para as universidades estatais.

\section{As garantias da Constituição Federal de 1988}

A gratuidade é um dos princípios do ensino ratificados pelo art. 206:

Art. 206. O ensino será ministrado com base nos seguintes princípios:

[...] IV - gratuidade do ensino público em estabelecimentos oficiais; [...]. (BRASIL, 1988). 
Embora o termo estabelecimentos oficiais porte certa ambiguidade (MURANAKA; MINTO, 1998, p. 74), a conexão entre "gratuidade do ensino público" e "estabelecimentos oficiais" é inequívoca. Assim, toda e qualquer instituição de ensino estatal, portanto oficial, deve ser gratuita.

Estudiosos do assunto não colocam isso em dúvida. Para Cunha (1991, p. 44), foi com a Constituição Federal de 1988 (CF 1988) que "pela primeira vez em nossa história, o ensino superior oferecido pelas universidades e faculdades públicas passou a ser gratuito de direito em todo o país", ao passo que, para Oliveira (2007, p. 24), o dispositivo do inciso IV "inova a formulação da gratuidade, assegurando-a para todos os níveis" e "declara-se, explicitamente, a gratuidade também para o ensino superior".

Corroborando essas interpretaçóes, Chrispino (2005, p. 222) afirma que, embora náo haja menção explícita na CF e na Lei de Diretrizes e Bases da Educação Nacional (LDB 1996), o princípio da gratuidade do ensino em estabelecimentos oficiais deve se estender também para o ES, prevalecendo a lógica da hierarquia legislativa. Este raciocínio é confirmado por um jurista:

O princípio da gratuidade do ensino público deve ser interpretado extensivamente, de modo que a expressão ensino abranja todas as atividades que norteiam e propiciem o ensino, pois embora ensino seja o fim, os meios que possibilitam o acesso a ele, lhes são inerentes, pois servem de amparo, suporte e até condição para a concretização do acesso ao ensino público e gratuito.

Assim, soa indubitável também que a Constituição veda a cobrança das demais taxas de serviços vinculados à atividade acadêmica, tais como expedição de diplomas, certificados, transferências, emissão de históricos escolares, avaliação curricular, trancamento parcial ou total de disciplina, cancelamento de disciplina, entre outros serviços prestados ao aluno (CASSIMIRO, 2009, grifos no original).

Sobre a abrangência da gratuidade no ES, Chrispino se ampara no texto da LDB 1996, que complementa a CF 1988, e conclui:

Percebe-se que a chamada Educação Superior é composta de quatro espécies distintas: cursos sequenciais (I), graduação (II), pós-graduação (III) e extensão (IV). Todos os cursos e programas, se desenvolvidos ou oferecidos por instituiçôes públicas de ensino devem submissäo ao Princípio da Gratuidade e, por tal, todos os cursos e programas deverão ser gratuitos. Em outras palavras, não poderá haver cobrança de mensalidades ou troca por serviços ou trabalhos. (CHRISPINO, 2005, p. 225, grifos nossos). 
Ainda quanto à extensão da gratuidade, o posicionamento de Oliveira é enfático:

Constitui infração o entendimento generalizadamente adotado atualmente em universidades públicas, de restringir a aplicação desse princípio apenas aos cursos regulares de graduação e pós-graduação stricto sensu, cobrando pelos de especialização e pós-graduação lato sensu (OLIVEIRA, 2007, p. 24) ${ }^{3}$.

\section{Abrangência da gratuidade}

Embora sejam crescentes as contestaçóes políticas e ideológicas da gratuidade, do ponto de vista jurídico, há razoável consenso de que o princípio do art. 206, IV, abrange os estabelecimentos oficiais de ES. Mas é um consenso restrito aos cursos de graduação e pós-graduação stricto sensu (mestrados e doutorados), havendo controvérsia quanto às demais atividades acadêmicas. Por isso, um dos motivos utilizados para justificar a instituição de cobranças variadas nas universidades estatais é que o texto constitucional não teria definido a abrangência do princípio da gratuidade.

Nas justificativas que acompanhavam a Proposta de Emenda Constitucional (PEC) n. 395/2014, de autoria do deputado Alex Canziani, o intuito de alterar o texto da CF 1988 se justificava precisamente por reconhecer sua não autorização à cobrança:

A presente iniciativa tem por objetivo excluir do princípio constitucional da gratuidade nos estabelecimentos oficiais, as atividades de extensão caracterizadas como cursos de treinamento e aperfeiçoamento, assim como os cursos de especialização (CANZIANI, 2014, p. 1).

$\mathrm{O}$ artifício utilizado por Canziani não era novo: como o art. 206 da CF, ao tratar da gratuidade, refere-se ao ensino, busca-se justificar que sua validade é restrita às atividades regulares (graduação e pós-graduação stricto sensu). Esta não é uma precisão exigida pela $\mathrm{CF}$, razão pela qual um conjunto significativo de IES estatais foi acionado na justiça para deter suas práticas de cobrança. O art. 206 estabelece os princípios que regem o ensino sem, contudo, referir-se a dimensões específicas da atividade de ensino.

Outrossim, o capítulo III do texto constitucional ("Da Educação, da Cultura e do Desporto"), em sua Seção I ("Da educação"), contém menções a dois termos - educação e ensino - que apenas numa leitura superficial poderiam ser entendidos como distintos. Num entendimento global da Seção, percebe-se que os termos ensino e educação podem ser interpretados sob um mesmo prisma; no limite, como sinônimos ${ }^{4}$. Vejamos alguns exemplos. 
Nas expressóes "profissionais do ensino" (art. 206, V, que com a Emenda n. 53/2006, tornou-se "profissionais da educação escolar"), "sistemas de ensino" (art. 211) e "manutenção e desenvolvimento do ensino" — MDE (art. 212), o termo ensino possui sentido abrangente, não adquirindo necessariamente a conotação de uma das dimensóes da educação. Fosse substituído por "educação", a redação permaneceria coerente, pois não faria sentido imaginar que União, estados e municípios destinem os recursos previstos apenas ao ensino, mas não à educação de forma geral; ou, ainda, que os sistemas seriam apenas de ensino, mas não de educação 5 . Em especial no caso do art. 212 da CF 1988, os art. 70 e 71 da LDB vieram a corroborar essa apreensão abrangente, haja vista que especificaram o significado de MDE, definindo o que poderia ser considerado como gasto com ensino.

Quanto às universidades, acrescenta-se uma especificidade, pois esse é um tipo de instituição que recebeu atenção distinta por parte dos legisladores na CF 1988:

Art. 207. As universidades gozam de autonomia didático-científica, administrativa e de gestão financeira e patrimonial, e obedecerão ao princípio de indissociabilidade entre ensino, pesquisa e extensão (BRASIL, 1988).

No art. 207, o ensino se diferencia apenas formalmente das atividades de pesquisa e extensão, pois com elas forma um conjunto indissociável. Aliás, a conexão entre os princípios de autonomia e indissociabilidade representou, segundo Catani e Oliveira, a concretização de uma "luta histórica do movimento dos educadores e da comunidade científica em geral”, e que indicava a intenção de:

Evitar a fragmentação das atividades acadêmicas desenvolvidas, bem como a repartiçáo ou a pulverização da oferta de bens e serviços acadêmicos com base em critérios alheios à lógica essencial de organização e de produçáo do trabalho que ocorre na universidade (CATANI; OLIVEIRA, 2002, p. 78-79).

Portanto, tanto no texto da lei quanto no espírito que orientou sua elaboração, não só se mantém a garantia do art. 206, IV ("gratuidade do ensino público em estabelecimentos oficiais") ${ }^{6}$, como, no caso das universidades oficiais ${ }^{7}$, garante-se a extensão da gratuidade ao conjunto de atividades exercidas por essas instituiçóes de forma indissociável — ensino, pesquisa e extensão.

\section{Pós-graduação lato sensu e extensão: atividades-fim ou atividades-arrecadatórias?}

Como os princípios constitucionais náo perderam validade, tomar a pesquisa e a extensão como atividades separadas do ensino (interpretando-o ao 
pé da letra e náo à luz do conjunto da norma constitucional), configura algo além da simples interpretação. Trata-se de um ardil que vem favorecendo mudanças concretas nas instituiçóes, sobretudo a partir das décadas de 1980 e 1990. Para Dal Rosso (2004), isso se deu num contexto de contingenciamento dos recursos públicos destinados às universidades, que assim foram "forçadas a produzir uma parte do seu sustento", com consequências inegáveis:

A constituição de setores de arrecadação de recursos dentro das universidades públicas alterou a estrutura de poder dentro das instituiçóes - a mão que guarda a chave do cofre, também controla o poder. Dentro dessa política de arrecadação de recursos, as universidades públicas também passaram a vender cursos de toda a ordem - hoje a universidade pública está, em boa medida, privatizada por dentro - jogando na lata do lixo o princípio da gratuidade do ensino público em estabelecimentos oficiais (DAL ROSSO, 2004, p. 481).

Deve-se registrar que a LDB 1996, de algum modo, favoreceu tal interpretação. Nela, prevaleceu uma concepção limitada de ensino, com ênfase na dimensão da transmissão (MURANAKA; MINTO, 1998, p. 67), o que facilitou interpretar a indissociabilidade como justaposiçãa ${ }^{8}$. $\mathrm{O}$ veto da expressão "vedada a cobrança de taxas escolares nos estabelecimentos oficiais de ensino", durante a tramitação da LDB, também motivou Brandão (2003, p. 24) a afirmar que a opçáo de colocar a gratuidade como princípio e não como obrigatoriedade podia "denotar uma intenção velada de, no futuro, privatizar todos os níveis de ensino que forem possíveis".

Num contexto de reformas gerencialistas, de privatização crescente e de ajustes estatais em prol de uma nova ordem global, intensificado a partir da metade dos anos 1990, o referido princípio constitucional foi perdendo força no ES. A reforma do Estado estimulou a diversificação desse ensino, conforme as diretrizes dos organismos internacionais, afastando-o ainda mais de uma perspectiva unitária e garantindo sua expansão ao sabor dos interesses econômicos hegemônicos.

A partir daí proliferaram práticas pautadas nesse artifício que desvincula, sobretudo, as atividades de pós-graduação lato sensu e de extensão, da rubrica ensino como forma de escapar das obrigaçóes constitucionais. Duas estratégias se destacam: a da cobrança direta nos cursos de pós-graduação lato sensu/especialização; a de incluir cursos de especialização como uma modalidade da extensão, onde há menor resistência à cobrança e na qual prevalece uma identidade de prestação de serviços. A pulverização de fundaçôes privadas de apoio às universidades estatais potencializou esse processo?.

Nas justificativas da PEC n. 395/2014, esse mote foi repetido, explicitando concepção nitidamente arrecadatória: 
Embora sejam, em última instância, atividades de ensino, geralmente se dirigem a públicos restritos, quase sempre profissionais e empregados de grandes empresas, constituindo importante fonte de receita própria das instituiçóes oficiais (CANZIANI, 2014, p. 1-2).

Ora, a prevalecer esse entendimento, atividades feitas a pretexto de extensão e pós lato sensu ${ }^{10}$ serão organizadas, cada vez mais, em função de seu potencial arrecadatório e não necessariamente como atividades-fim das universidades.

\section{Ação legitimadora do Conselho Nacional de Educação}

Tudo isso não ocorreu, evidentemente, sem resistências: houve mobilização e contestaçóes diversas, na comunidade acadêmica e fora dela ${ }^{11}$. Em certo sentido, essas resistências se tornaram estopim para açóes judiciais que, num momento seguinte, obrigaram o Ministério Público Federal (MPF) a pedir esclarecimentos ao Ministério da Educação (MEC), que então remeteu a demanda ao Conselho Nacional de Educação (CNE) (CHRISPINO, 2005, p. 226-227).

No Parecer exarado pela Câmara de Educação Superior do CNE, de n. 0364/2002 (BRASIL, 2002), lavrado pelos conselheiros Edson Nunes, Jacques Schwartzman e Roberto Frota, concluiu-se pela legalidade das cobranças nas atividades de extensão e de pós-graduação lato sensu. Alegou-se, na ocasião, que essas atividades de ensino se distinguiam como não regulares (passíveis de certificação) e de oferta não contínua por parte das instituiçôes de ensino, ao passo que a graduação e a pós-graduação regulares seriam passíveis de conferir graus acadêmicos.

Crítico dessa argumentação, Chrispino afirma que:

O parecer vota pela regularidade da cobrança a partir de uma definição arbitrária - e não consensual — de que os níveis de ensino que conferem diplomas náo podem ser cobrados mas aqueles cursos que resultam em formação mais estreita, e que segundo eles conferem certificados, podem ser cobrados (CHRISPINO, 2005, p. 227).

No mesmo Parecer argumentava-se que, sem ferir os princípios do art. 206, IV, da CF 1988, dever-se-ia reconhecer que este não estabelecera "a precisa amplitude deste imperativo constitucional". Tendo como motivo os cursos de pós-graduação lato sensu nas universidades oficiais, apresentava-se o entendimento de que esses não demandavam aplicação do art. 206. Os relatores se manifestaram assim: 
De certa maneira, os cursos de especialização em todas as formas previstas, os de aperfeiçoamento e até os de extensão, fazem parte de um mesmo grupo de educação continuada, cujas características principais são a oferta descontínua, episódica e, na maioria dos casos, não acadêmica, conduzindo a certificado. "Vale dizer, tais cursos contrastam com definição de ensino, aproximando-se, muito mais, do conceito de extensão", conforme argumenta a Informação SESU, número 57, anteriormente mencionada, o que tem levado, por decorrência, à compreensão de que se tratam de cursos livres que independem, exceto no caso de entidades não educacionais, de prévia autorização e de continuada supervisão (BRASIL, 2002, p. 5, grifos nossos).

Vê-se que a manifestação do CNE acabou por corroborar a interpretação da extensão e parte da pós-graduação como domínios apartados do ensino e que, por isso, não estariam subordinados ao princípio constitucional da gratuidade. Vejamos, entretanto, o que a LDB $1996 \mathrm{diz}$ sobre as atividades de extensão:

Art. 43. A educação superior tem por finalidade: [...]

VII - promover a extensão, aberta à participação da população, visando à difusão das conquistas e benefícios resultantes da criação cultural e da pesquisa científica e tecnológica geradas na instituição. [...] (BRASIL, 1996).

A LDB define que a extensão é uma finalidade da educação superior, não apenas das universidades, com a precisa indicaçáo de que tais atividades sejam "abertas à participação da população" (BRASIL, 1996), o que fortalece o princípio da gratuidade num país tão desigual como o Brasil. No caso das universidades, não se deve esquecer que isso está vinculado ao princípio da indissociabilidade, ou seja, a atividade-fim das universidades não é apenas $o$ ensino, $a$ pesquisa e $a$ extensão, mas sua relação de indissociabilidade.

Os argumentos usados em favor das cobranças (lato sensu e extensão) baseiam-se, portanto, na tentativa de retirar algumas das atividades de ensino do âmbito e regramentos institucionais a que obedecem nas universidades oficiais. Por isso, ora o acento recai sobre a tese de que apenas a proibição constitucional de cobrar pelo ensino regular é inquestionável, ora se tenta arbitrar sobre a própria finalidade do ensino, com o que se interpreta o princípio da gratuidade de forma a hierarquizar os cursos: alguns seriam de interesse social e universal (regulares), e outros, de interesse privado e empresarial (não regulares) ${ }^{12}$. Em ambos os casos, predomina uma visão circunscrita ao objetivo de arrecadar recursos extraorçamentários para as IES. ${ }^{13}$ 


\section{Um princípio flexível?}

Já mencionamos que uma única exceção ao inciso IV, do art. 206, foi prevista na CF 1988 (art. 242). Portanto, para todos os demais casos envolvendo o ensino público em estabelecimentos oficiais de ensino, prevalece o indicado por Cassimiro:

O ensino público constitui atividade estatal de caráter uti universi, destinada a beneficiar a populaçáo em geral, indistintamente, devendo ser custeado por meio de impostos e não por meio de taxas, não podendo as Universidades Públicas instituir óbices financeiros para o acesso ao ensino público e gratuito, com a instituiçáo de taxas, sob pena de incorrer em inconstitucionalidade (CASSIMIRO, 2009, grifos nossos).

Ainda sobre a interpretação dada pelo Parecer CNE/Câmara da Educação Superior (CES), de 2002, Chrispino (2005, p. 227) acrescenta que os "Princípios [do art. 206] não estipulam o que pode ou o que não pode ser cobrado, eles indicam o ensino público gratuito em instituiçóes públicas. Ponto final”. Ao se adotar qualquer flexibilização arbitrária, muitos questionamentos se tornam possíveis, inviabilizando a própria noção de princípio. Apesar disso, resoluções posteriores do próprio CNE, como a de n. 5, de 25 de setembro de 2008 (BRASIL, 2008), referendaram esse entendimento que dá ao conselho a prerrogativa de definir a abrangência de um princípio constitucional ${ }^{14}$.

A nosso ver, uma interpretação global do capítulo III da CF 1988 exige a apreciação da educação como direito social em todos os níveis e etapas. Noutros termos: do fato de a CF não estender a obrigatoriedade (portanto, o direito público subjetivo) ao ES - o que nem faria sentido - náo decorre que, uma vez submetido às regras do funcionamento do ensino em instituiçôes oficiais, os seus princípios possam ser desrespeitados. Aquilo que o art. 206 estabelece também será válido para o ES, excetuados os casos previstos no art. 242, tendo por diferença o fato de que o Poder Público não é obrigado a oferecê-lo para todos.

Em reforço a essa posição, lembramos de outro artigo da CF 1988:

Art. 208. O dever do Estado com a educação será efetivado mediante a garantia de: [...]

$\mathrm{V}$ - acesso aos níveis mais elevados do ensino, da pesquisa e da criação artística, segundo a capacidade de cada um (BRASIL, 1988).

Nada indica que a expressão segundo a capacidade de cada um deixe abertura para a exigência de contrapartida financeira individual (cobrança de taxas, mensalidades). O dever do Estado, pois, é o de garantir o acesso aos níveis mais elevados do ensino e da pesquisa a todos que conseguirem chegar nesses níveis. 
Ora, não é exatamente isso que se argumenta quando o Estado exerce tal dever mediante a compra de vagas no ES privado, eliminando ou atenuando o ônus do custeio individual? $\mathrm{Na}$ exposição de motivos da Medida Provisória (MP) que criou o Programa Universidade Para Todos (Prouni), os ministros Haddad e Palocci Filho afirmavam que a MP visava a "dar à educação superior um status diferenciado", intentando "elevá-la à categoria de bem essencial e que, destarte, não poderia se submeter ao regime tributário e fiscal indistintamente aplicável à atividade empresarial orientada pela mercadoria e pelo consumo" (BRASIL, 2004). Por fim, justificavam que era de amplo conhecimento que os tributos cobrados de IES privadas eram repassados aos estudantes por meio das mensalidades e que, assim, o Prouni deveria ser entendido como "política de acesso democrático ao ensino superior — para estudantes de baixa renda e também para minorias étnico-raciais" (BRASIL, 2004).

\section{Concepções de público em disputa}

As confusões e/ou distintas interpretações sobre gratuidade não são fortuitas. Trata-se de uma disputa político-ideológica que se intensificou a partir da Reforma do Estado nos anos 1990. Ademais, tentativas de ressignificar a autonomia sob o prisma da administração estatal de base neoliberal têm sido usadas para confundi-la com (des)responsabilização do poder público, reduzindo-a a formas de obter fontes alternativas de financiamento da educação. Esse foi o contexto no qual as alteraçóes/burlas dos princípios constitucionais foram progressivamente ganhando terreno. Lembremos do relativismo teórico proposto por Bresser-Pereira (1997) ao definir que propriedade pública é aquela cuja função é dedicar-se ao interesse público, ou seja, "que deve ser de todos e para todos" e que, por isso, "não visa o lucro" quando de direito privado.

No intuito de disseminar e/ou manter as cobranças já praticadas na extensão e na pós-graduação lato sensu em IES estatais, preservando a gratuidade para o ensino regular, argumenta-se também que, sem a cobrança, essas atividades se tornariam inviáveis ${ }^{15}$, pois não previstas nos orçamentos públicos. Seria, também, uma forma de ampliar os recursos disponíveis para as IES mantidas pelo poder público, de modo a desonerar seus orçamentos e fortalecer as atividades regulares.

Embora se manifestem de muitas maneiras, esses argumentos têm em comum o fato de nunca problematizarem que essas atividades - componentes do tripé ensino-pesquisa-extensão — não têm recebido recursos financeiros suficientes. Ou seja, problemas decorrentes de subfinanciamento são transformados na principal motivação/justificação para as cobranças, numa espécie de chantagem financeira que parte do pressuposto de que essas atividades são um bônus que as instituiçóes podem oferecer, desde que cobrem à parte. 
Nada disso desobriga as IES estatais de se submeterem aos princípios do art. 206 da CF 1988. A própria LDB 1996 instituiu dispositivos que interditam essa possibilidade:

Art. 53. No exercício de sua autonomia, são asseguradas às universidades, sem prejuízo de outras, as seguintes atribuiçóes:

I - criar, organizar e extinguir, em sua sede, cursos e programas de educação superior previstos nesta Lei, obedecendo às normas gerais da União e, quando for o caso, do respectivo sistema de ensino; [...]

Parágrafo único. Para garantir a autonomia didático-científica das universidades, caberá aos seus colegiados de ensino e pesquisa decidir, dentro dos recursos orçamentários disponíveis, sobre:

I - criação, expansão, modificação e extinção de cursos;

II - ampliação e diminuição de vagas; [...]

IV - programaçáo das pesquisas e das atividades de extensão (BRASIL, 1996, grifos nossos).

A cobrança pelas atividades de ensino, pesquisa ou extensão não é autorizada pela LDB. Com efeito, o que o parágrafo único do art. 53 estabelece é um limite para a autonomia: o orçamento disponível. Portanto, não cabe às IES, às suas unidades ou aos órgãos colegiados utilizar o argumento da escassez de recursos, pois, a rigor, as atividades a serem realizadas subordinam-se aos recursos orçamentários disponiveis.

\section{Considerações}

Mesmo sem jamais ter sido consensual, a gratuidade do ES em IES oficiais é uma conquista social, cujo peso é ainda maior num país de acesso restrito à escolarização nos níveis mais elevados. Decerto, o que mobiliza tantas resistências não está, de modo algum, restrito a problemas técnicos/financei$\operatorname{ros}^{16}$. Deve-se, então, perguntar: a quem interessa flexibilizar as regras - por mudanças efetivas ou interpretaçóes do texto legal - que determinam, no topo do ordenamento jurídico, a gratuidade do ensino nas instituiçóes oficiais? Diante do fato de que tal ordenamento já favorece o interesse privado mercantil ${ }^{17}$, não caberia às instituiçóes oficiais e ao Estado fortalecer aquele segmento do ES que mais vem perdendo espaço ao longo das últimas décadas? Cobranças seletivas contribuem ou prejudicam o ES oficial?

Não se pode aceitar que, à conta de práticas pretensamente modernizantes, institua-se uma narrativa oficial na qual a gratuidade ampla e irrestrita do ES seja tratada como produto de uma suposta injustiça eterna da sociedade brasileira, a favorecer os/as filhos/as das classes dominantes. É o que se diz há décadas ${ }^{18}$ : "É tão arraigada a ideia de que educação superior pública brasileira é regressiva 
que poucos se deram ao trabalho de verificar se é mesmo e em que medida" (WALTENBERG, 2017, p. 49).

Estudos como o de Waltenberg (2017) e de Helene (2013), amparados em dados objetivos, colocam em xeque algumas das alegadas verdades sobre o ES estatal no Brasil. Reforçam, ademais, que sem uma visão abrangente, os argumentos utilizados em defesa das práticas de cobrança são frágeis. Sem um quadro de problemas que envolva o caráter regressivo do sistema tributário, a ausência de controles públicos sobre o ensino privado, o problema da dívida pública e seus encargos crescentes, a desigualdade educacional existente no país, o subfinanciamento do ES estatal, entre outros, qualquer saída proclamada para o ES pode se reduzir a mera retórica que visa a ocultar interesses.

Num país cujo ES se situa entre os mais privatizados do mundo, em que medida a cobrança seletiva (extensão e lato sensu) não contribui para reforçar as propostas retrógradas de cobrança do ES como um todo?

Para tentar responder a isso, julgamos pertinentes as indicaçóes que Dias Sobrinho (2002) nos deu ao comentar, por um lado, sobre o relaxamento do Regime de Dedicação Integral à Docência e à Pesquisa (RDIDP) e, por outro lado, sobre a prática de vender serviços como alternativa legalizada e estimulada em muitas IES estatais:

Todos se socorrem dos argumentos do papel social da universidade, ainda que muitas dessas açóes, quando não institucionais e não articuladas a um projeto coletivo e acadêmico, beneficiem, na maioria dos casos, os interesses apenas dos indivíduos que as praticam. Mesmo que se trate de uma instituição pública, náo há como não perceber em tudo isso valores, interesses e disposiçôes de empresas de natureza econômica impregnando o currículo oculto e consolidando uma mentalidade geral favorável ao mercado, ou quase (DIAS SOBRINHO, 2002, p. 173).

Quando as cobranças se combinam com práticas de complementação salarial (podendo infringir os regimes de dedicação exclusiva dos docentes, além de intensificar o seu trabalho e dos funcionários, com possíveis prejuízos aos padróes de qualidade estabelecidos) e entradas de recursos privados nas universidades estatais que não se submetem às regras dos orçamentos públicos advindos da receita de impostos, entre outras, temos formas de reduzir o caráter público das IES estatais.

Além disso, as cobranças que estamos chamando aqui de seletivas, a nosso ver, jogam água no moinho da defesa pelo fim da gratuidade no ES oficial, movida por mistificaçóes como a de que a existência de contrapartida individual nas IES estatais seria comum nos países mais desenvolvidos e ricos, haja vista que o retorno trazido pelo ES é considerado de natureza mais individual, enquanto que os retornos 
trazidos pela formação básica seriam mais coletivos e sociais; de que no ES estatal, por atender proporcionalmente mais pessoas com nível de renda suficiente para custear a própria formação do que pessoas sem essas condiçóes, a gratuidade teria um efeito regressivo para o contribuinte mais pobre. Por fim, renova o apelo recorrente à suposta insustentabilidade do ES — chamado equivocadamente de "modelo único" - praticado pelas universidades brasileiras oficiais (ensino/pesquisa/extensão).

Disfarçadas de fontes alternativa de receitas, de uma autonomia ressignificada ou, ainda, de democratização, essas cobranças tentam tirar o foco do retrocesso seletivista e elitizante em curso, que poderá penalizar parcelas da população trabalhadora - que não poderão custear os estudos - embora, igualmente, financiem as IES estatais via pagamento de impostos. Isso ocorre num momento em que estudos e dados disponíveis mostram que ser gratuito já não é sequer condição suficiente para que a expansão do ES atinja novos patamares. ${ }^{19}$

Por fim, lembramos do provocativo alerta feito por Tragtenberg, em 1978 , sobre o perigo de reduzir a universidade ao tecnicismo e aos interesses econômicos hegemônicos, o que entendia ser um fator de delinquência acadêmica:

Uma universidade que produz pesquisas ou cursos a quem é apto a pagá-los perde o senso da discriminação ética e da finalidade social de sua produção - é uma multiversidade que se vende no mercado ao primeiro comprador, sem averiguar o fim da encomenda, isso coberto pela ideologia da neutralidade do conhecimento e seu produto (TRAGTENBERG, 2004, p. 16).

É preciso fazer escolhas: tergiversar sobre as cobranças e suas consequências sobre o caráter público do ES estatal é, de muitas maneiras, compactuar com a delinquência.

\section{Notas}

1. Sobre isso ver Fávero (1992) e Minto (2006).

2. A Proposta de Emenda Constitucional (PEC) n. 395/2014 foi aprovada pelo Senado, mas derrotada na Câmara dos Deputados em 29/03/2017, seguida de imediato arquivamento. Essa PEC alterava a redaçáo do art. 206, IV, da CF 1988, para explicitar a diferença entre cursos regulares e não regulares, assunto que será retomado adiante. No Senado, tramita o Projeto de Lei do Senado (PLS) n. 782/2015, de autoria do senador Marcelo Crivella, que pretende instituir pagamento de anuidade em IES estatais para estudantes com renda familiar acima de 30 salários-mínimos.

3. Embora não seja nosso objetivo, é lícito questionar se o princípio de publicidade, estabelecido no art. 37 da CF 1988, também não é violado na cobrança pelas atividades (ou parte delas) ofertadas nas instituiçóes oficiais. Sobre isso ver Vieira (2001, p. 27). 
4. Isso não quer dizer que são idênticos. Trata-se de apontar que o texto constitucional, por suas características e forma de elaboração, foi produzido a fim de não ressaltar essas distinções (o mesmo ocorrendo na LDB 1996). Com isso, torna-se precipitada a interpretaçáo de ensino como sendo apenas uma das dimensões do que também no texto se chama de educação. Sobre os problemas jurídicos decorrentes da "ambiguidade terminológica" das leis, ver Ranieri (2000, p. 166-168).

5. Há décadas, importantes debates e lutas vêm sendo feitos por movimentos da área educacional, em defesa da construção de um sistema nacional de educação.

6. A única exceção está no art. 242: "O princípio do Art. 206, IV, não se aplica às instituiçóes educacionais oficiais criadas por lei estadual ou municipal e existentes na data da promulgação desta Constituição, que não sejam total ou preponderantemente mantidas com recursos públicos" (BRASIL, 1988).

7. Optamos por utilizar o mesmo termo do art. 206 quando nos referimos às universidades mantidas, total ou preponderantemente, pelo Poder Público.

8. A rigor, a LDB não reafirmou o texto da CF 1988 nessa questão (MURANAKA; MINTO, 1998, p. 70-71).

9. Sobre o processo de expansão das fundaçôes, ver Sguissardi (2009, p. 78-108).

10. Deve-se evitar generalizaçóes, pois nem todas as atividades em extensão e pós lato sensu interessam a esse setor de arrecadação que se formou nas IES estatais.

11. O movimento docente e suas entidades sindicais foram os principais sujeitos dessa resistência.

12. Ainda que discordemos de sua interpretação, Ranieri (2000, p. 236-240) destaca-se entre os autores que defendem a possibilidade de cobrança de certas atividades de ensino. A autora argumenta que a regulamentação do financiamento da educação na LDB 1996 relativiza o princípio de gratuidade ao não autorizar gastos específicos em manutenção e desenvolvimento do ensino (art. 70 e 71). Assim, as atividades de extensão praticadas a título de assistência social (art. 71, II e IV), bem como as pesquisas com finalidades externas às instituiçóes (art. 71, I), criam circunstâncias em que "poderiam ser cobrados alguns cursos oferecidos pela universidade pública” (RANIERI, 2000, p. 239) sem implicar quebra da ordem constitucional e legal, conclui a autora.

13. O molde dessa lógica estava bem delineado na proposta das Organizaçóes Sociais do Ministério da Administração Federal e Reforma do Estado (MARE)(BRASIL, 1998).

14. Essa estende a autorização para ofertar cursos de pós-graduação lato sensu às instituições não educacionais.

15. Após o arquivamento da PEC 395/2014, um conjunto de 17 organizaçóes ligadas ao campo científico, dirigentes de universidades, fundaçóes de apoio, entre outras, publicaram uma carta-manifesto (CARTA ABERTA..., 2017) exortando o Supremo Tribunal Federal a julgar legítima a cobrança dos cursos de pós lato sensu, sob o argumento de que a prática era legítima e - supostamente — a única alternativa de sobrevivência desses cursos. 
16. Estudos publicados pelo IPEA (2017) apresentam propostas alternativas para a gratuidade.

17. Pesquisadores de referência no campo das políticas para o ES, como Dias Sobrinho (2002) e Sguissardi e Silva Júnior (2009), corroboram essa afirmação.

18. As diretrizes do Banco Mundial e as propostas para o ES durante a Ditadura são expressōes disso. A recorrência com que a temática tem surgido nos veículos de imprensa, nos dias atuais, reforça essa apreensão.

19. Sobre isso ver Amaral (2016).

\section{Referências}

AMARAL, N.C. A educação superior brasileira: dilemas, desafios e comparaçôes com os países da OCDE e do BRICS. Revista Brasileira de Educação, Rio de Janeiro, v. 21, n. 66,p. 717-736, jul.-set. 2016.

BRANDÃO, C. da F. $L D B$ : passo a passo: lei de diretrizes e bases da educaçáo nacional (LDB no 9.394/96) comentada e interpretada artigo por artigo. Sáo Paulo: Avercamp, 2003.

BRASIL. Casa Civil. Exposição Interministerial no 061/2004/MEC/MF, de 10 set. 2004. 2004. Disponível em: <http:/www.planalto.gov.br/ccivil 03/ Ato2004-2006/2004/ Exm/EMI-061-MEC-MF-04.htm>. Acesso em: 15 maio 2017.

. Constituição da República Federativa do Brasil de 1988. Brasília: Senado Federal, 1988.

Lei no 9.394, de 20 dez. 1996. Estabelece as diretrizes e bases da educação nacional. Brasília: Senado Federal, 1996.

Ministério da Administração Federal e Reforma do Estado. Organizaçôes sociais. 5. ed. Brasília: Ministério da Administração Federal e Reforma do Estado, 1998. (Cadernos MARE da Reforma do Estado,v. 2.)

- Ministério da Educação. Conselho Nacional de Educação/Câmara da Educação Superior.Parecer $n^{\circ}$ 0364/2002, de 6 nov. 2002. Regularidade da cobrança de taxas em cursos de Pós-graduação, lato sensu, com base no art. 90, da Lei no 9.394. Brasília, 2002. Disponível em: <http://portal.mec.gov.br/dmdocuments/parecer cne 0364 sesu.pdf>. Acesso em: 7 abr. 2017.

Ministério da Educação. Conselho Nacional de Educação/Câmara da Educação Superior. Resolução no 5, de 25 set. 2008. Estabelece normas para o credenciamento especial de Instituições não educacionais para oferta de cursos de especialização. Disponível em: <portal.mec.gov.br/cne/arquivos/pdf/2008/rces005 08.pdf>. Acesso em: 7 abr. 2017.

BRESSER-PEREIRA, L.C. Estratégia e estrutura para um novo Estado. Revista de Economia Politica, v. 17, n. 3 (67), jul.-set. 1997.

CANZIANI, A.Proposta de emenda à Constituição n. 395, de 09/04/2014. Altera a redação do inciso IV do art. 206 da Constituição Federal, referente à gratuidade do ensino público em estabelecimentos oficiais.Brasília: Câmara dos Deputados, abr. 2014. Disponível em: <http://www.camara.gov.br/proposicoesWeb/fichadetramitacao?idProposicao=611966>. Acesso em: 22 maio 2017. 
CARTA ABERTA À SOCIEDADE BRASILEIRA.Quando a universidade pública perde, a sociedade perde. 7 abr. 2017. Disponível em: <http://www.sbpcnet.org.br/site/arquivos/ arquivo 691.pdf >. Acesso em: 23 maio 2017.

CASSIMIRO, B.G.A. Da inconstitucionalidade da cobrança de taxas em universidades públicas. Jus Navigandi, Teresina, ano 14, n. 2.366, 23 dez. 2009. Disponível em: < https:// jus.com.br/artigos/14067>. Acesso em: 7 abr. 2017.

CATANI, A.M.; OLIVEIRA, J.F. A educação superior. In: OLIVEIRA, R.; ADRIÃO, T. (Orgs.). Organização do ensino no Brasil: níveis e modalidades na Constituição Federal e na LDB. São Paulo: Xamã, 2002.

CHRISPINO, A. Ensino público gratuito: flexibilidades e desvios. Ensaio: Avaliação de Políticas Públicas da Educação, Rio de Janeiro, v. 13, n. 47, p. 217-234, abr.-jun. 2005.

CUNHA, L.A. A gratuidade do ensino superior público: da proibiçáo à garantia constitucional.In: VELLOSO, J. (Org.). Universidade pública: política, desempenho, perspectivas. Campinas: Papirus, 1991. p. 31-55.

. O público e o privado na educação superior brasileira: fronteira em movimento? In: TRINDADE, H. (Org.). Universidade em ruinas: na república dos professores. Petrópolis: Vozes, 1999. p. 39-56.

DAL ROSSO, S. Sustentação econômica das universidades públicas e gratuidade. Sociedade e Estado, Brasília, v. 19, n. 2, p. 479-487, jul.-dez. 2004.

DIAS SOBRINHO, J. Universidade e avaliação: entre a ética e o mercado. Florianópolis: Insular, 2002.

FÁVERO, M. de L.A. Em defesa da universidade pública. In: BRANDÃO, Z. et al. (Org.). Universidade e educação. Campinas: Papirus/Cedes; São Paulo: Ande/Anped, 1992. p. 121-133.

HELENE, O. Um diagnóstico da educação brasileira e de seu financiamento. Campinas: Autores Associados, 2013.

INSTITUTO DE PESQUISA ECONÔMICA APLICADA (IPEA). Radar: tecnologia, produção e comércio exterior. Brasília: IPEA, 2017.

MINTO, L.W. As reformas do ensino superior no Brasil: o público e o privado em questão. Campinas: Autores Associados, 2006.

MURANAKA, M.A.S.; MINTO, C.A. O capítulo “Da Educação Superior” na LDB uma análise. Universidade e Sociedade, Brasília, ano VIII, n. 15, p. 65-75, fev. 1998.

OLIVEIRA, R.P. de. O direito à educação. In: OLIVEIRA, R.P. de; ADRIÃO, T. (Orgs.). Gestâo, financiamento e direito à educação. 3. ed. São Paulo: Xamã, 2007. p. 15-41.

RANIERI, N.B.Educação superior, direito e Estado: na Lei de Diretrizes e Bases (Lei no 9.394/96). São Paulo: Edusp, Fapesp, 2000.

SGUISSARDI, V. Universidade brasileira no século XXI: desafios do presente. São Paulo: Cortez, 2009.

SGUISSARDI, V.; SILVA JR., J. Trabalho intensificado nas federais: pós-graduação e produtivismo acadêmico. Sáo Paulo: Xamá, 2009. 
TRAGTENBERG, M. A delinquência acadêmica. In: Sobre educação, politica e sindicalismo. 3. ed. São Paulo: Editora Unesp, 2004. p. 11-19.

VIEIRA, E. A política e as bases do direito educacional.Caderno Cedes, Campinas, ano XXI, n. 55, p. 9-29, nov. 2001.

WALTENBERG, F. Cursos em estabelecimentos públicos de ensino superior devem permanecer gratuitos. In: INSTITUTO DE PESQUISA ECONÔMICA APLICADA (IPEA). Radar: tecnologia, produção e comércio exterior. Brasília: IPEA, 2017. p. 27-31.

Recebido em 19 de junho de 2017.

Aceito em 08 de agosto de 2017. 